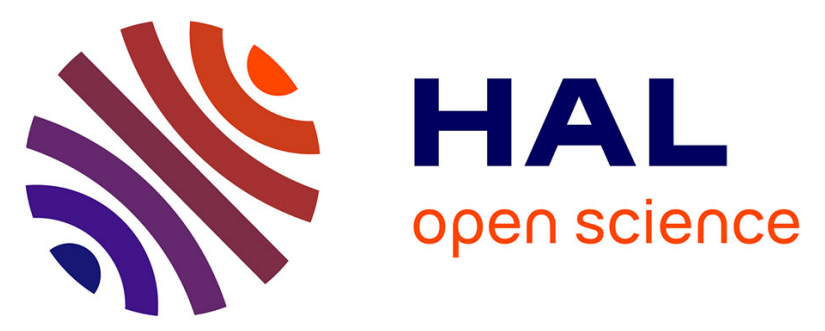

\title{
Taste acuity of obese adolescents and changes in food neophobia and food preferences during a weight reduction session.
}

Marie-Odile Monneuse, Natalie Rigal, M.-L. Frelut, Claude Marcel Hladik, Bruno Simmen, Patrick Pasquet

\section{To cite this version:}

Marie-Odile Monneuse, Natalie Rigal, M.-L. Frelut, Claude Marcel Hladik, Bruno Simmen, et al.. Taste acuity of obese adolescents and changes in food neophobia and food preferences during a weight reduction session.. Appetite, 2008, 50, pp.302-327. hal-00551893

\section{HAL Id: hal-00551893 \\ https://hal.science/hal-00551893}

Submitted on 4 Jan 2011

HAL is a multi-disciplinary open access archive for the deposit and dissemination of scientific research documents, whether they are published or not. The documents may come from teaching and research institutions in France or abroad, or from public or private research centers.
L'archive ouverte pluridisciplinaire HAL, est destinée au dépôt et à la diffusion de documents scientifiques de niveau recherche, publiés ou non, émanant des établissements d'enseignement et de recherche français ou étrangers, des laboratoires publics ou privés. 


\title{
Taste acuity of obese adolescents and changes in food neophobia and food preferences during a weight reduction session.
}

\author{
Marie-Odile Monneuse ${ }_{a *}$, Natalie Rigal b, Marie-Laure Frelut c, Claude-Marcel Hladik \\ d, Bruno Simmen ${ }_{a}$, Patrick Pasquet ${ }_{a}$
}

${ }^{a} U M R$ CNRS/MNHN 5145: Eco-Anthropologie et Ethnobiologie, Musée de l'Homme, 17 place du Trocadéro, 75116 Paris, France; monneuse@mnhn.fr; ppasquet@mnhn.fr

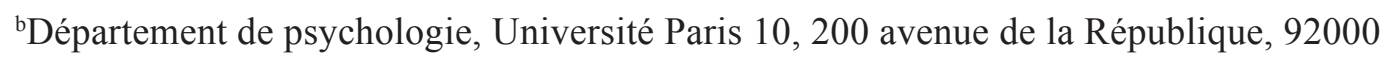

Nanterre, France; nrigal@wanadoo.fr

'Saint Vincent de Paul University Hospital, avenue Denfert-Rochereau, 75014 Paris, France et Centre thérapeutique pédiatrique, 95580 Margency, France; frelut@clubinternet.fr

dUMR CNRS/MNHN 5145: Eco-Anthropologie et Ethnobiologie, 4 avenue du petit château, 91800 Brunoy, France; hladik@mnhn.fr; simmen@mhnh.fr

\section{Key words}

Taste recognition threshold, taste perceived intensity, PROP, obesity, adolescent, weight reduction program, neophobia, food liking, fruits and vegetables

\begin{abstract}
The relationship between taste acuity and food neophobia, food familiarity and liking has been studied in the context of a residential Weight Reduction Session (WRS, mean duration: 10 months) in 39 obese adolescents. Taste acuity was assessed using recognition thresholds for sucrose, citric acid, sodium chloride and 6-nprophylthiouracyl (PROP) and supra-threshold perceived intensities for sucrose, sodium chloride and PROP. Food neophobia was assessed by using the Food Neophobia Scale at the beginning and at the end of the WRS. At the same times, a Food Familiarity and Liking Questionnaire was used to assess changes in food familiarity and likes or dislikes for different food categories. Taste acuity appeared to mediate behavioural food-related changes during the WRS. High taste acuity was associated with limited reductions in food neophobia; less sensitive subjects showed greater increases in the acceptability of healthy foods, especially fruits and vegetables. Therefore, taste perception (and particularly PROP perception) appears to be a predictor of the magnitude of food-related behavioural change achieved during a Weight Reduction Session.
\end{abstract}




\section{Introduction}

It has been suggested that taste sensitivity is related to food neophobia (the reluctance to taste novel foods). Carter, Donley, Sonson, Santaniello, Staley, \& Raudenbush (2000) observed an association with the genetically determined sensitivity to the bitter tasting substance PTC (phenylthiocarbamide), with food neophobic subjects exhibiting greater sensitivity than neophilic ones. In the same vein, some of us (Pasquet, Oberti, El Ati, \& Hladik, 2002) reported that adult subjects significantly differ in food preferences as a function of PROP (6- $n$ propylthiouracyl) sensitivity; the subjects with the highest sensitivity used a limited set of foods and were assumed to have difficulties overcoming an inherent food neophobia. In addition to sensory factors, it has been proposed that body weight, among other physiological factors, could be related to food neophobia (Raudenbush, Corley, Flower, Kozlowski, \& Meyer, 2003).

We recently reported (Rigal, Frelut, Monneuse, Hladik, Marez, Simmen, \& Pasquet, 2006) that in obese adolescents the food repertoire and preferences for some food categories, such as fruits and vegetables, breakfast foods or calorie-reduced foods, can be significantly increased as a result of an educational program during a residential Weight Reduction Session (WRS). During such a session, the food neophobia score, as evaluated by the Food Neophobia Scale, (FNS, Pliner \& Hobden, 1992) also decreases with exposure to a food variety wider than that obese adolescents may usually obtain at home. Nevertheless neophobia appears to be an individual temperament trait whose expression changes little throughout the lifetime. To what extent could taste perception mediate the dynamics of such attitudinal changes induced by a change in dietary experience?

In this communication we present the results of a study of the relationship between taste acuity and changes in behavioural traits vis-à-vis food during this weight reduction session.

\section{Subjects and methods}

\section{Study context and ethics}

The study was carried out at the Margency Clinical Centre, near Paris (France), where massively obese adolescents stayed for the Weight Reduction Session (WRS). Together with their school training, they followed an educational program combining a balanced diet that included a wide variety of foods, nutritional lectures and daily physical activities, with the goal to substantially reduce their excess body weight. Details on WRS and results concerning food neophobia in adolescents tested in 2000 and 2001 ( $\mathrm{n}=72)$ are presented in Rigal et al, (2006). In the present study, we consider exclusively the 39 subjects followed in 2001, in whom taste acuity was assessed. Measurements were carried out at the beginning (T1) and before the end (T2) of the WRS, with a mean time interval of $10.4 \pm 4.4$ months between T1 and T2. 
This study was conducted in accordance with the Helsinki II declaration. Oral consent was required for all subjects after the parents were informed of our goals and methods, and a consent form was signed by all subjects and/or their parents.

\section{Participants}

Adolescents of both sexes participated, 28 girls and 11 boys, aged 10.5 to 17.5 years (mean 14.7 y.). All girls were post-menarcheal, whereas among boys, four were sexually mature, following stages for genital and pubic development (Tanner,1962). Mean Body Mass Index (BMI) was $39.5 \mathrm{~kg} / \mathrm{m}^{2}$ (ranging from 30.9 to 51.6) at T1 and $29.7 \mathrm{~kg} / \mathrm{m}^{2}$ (ranging from 22.1 to 42.1 ) at T2. BMI for age was expressed in terms of Z-scores using the sex-specific CDC BMI for age reference curves (Centre for Disease Control, 2000). The figures are 2.47 (ranging from 2.02 to 2.99 ) at $\mathrm{T} 1$, and 1.75 (ranging from 0.48 to 2.59 ) at $\mathrm{T} 2$.

Most adolescents under investigation were members of families with a low income relative to the French average. All attended secondary school.

\section{Measurement of taste acuity}

Taste acuity was assessed via taste recognition thresholds and supra-threshold perceived intensity ratings.

Recognition thresholds: Determination of taste recognition thresholds was carried out using series of four pure chemicals in solution in a commercial drinking water selected for its low mineral content. Sucrose (10 solutions: 2.0-1000 mM) and citric acid (8 solutions: $0.20-25 \mathrm{mM})$ were diluted in binary step series (0.3 log-step), whereas the solution series of sodium chloride (12 solutions: $1.77-1000 \mathrm{mM}$ ) and PROP (6- $n$-prophylthiouracyl) (15 solutions: 0.001-3.2 $\mathrm{mM}$ ) were created using 0.25 log-steps. The testing procedure was the staircase-method modified from Cornsweet (1962) as follows: each subject was first informed of the taste categories he or she could be faced with (water, salty, sweet, bitter or acid). The four series of solutions were presented one after another, in a random order to which the subject was blind. Within each series, the solutions were presented in order of ascending concentrations, and sipped by the assessor from a 2-ml plastic teaspoon. They were not swallowed, and the mouth was rinsed between solutions with the same water as was used to prepare the test solutions. The assessor had to correctly name the taste in each series. Once the taste of two successive concentrations was recognised successfully, the subject was given the highest previously unrecognised concentration (first reversal). This up-anddown procedure was performed twice until the taste of two increasing stimuli was correctly named. The actual recognition threshold was calculated as the mean of the lowest concentrations recognised in each ascending run (Pasquet, Monneuse, Simmen, Marez, \& Hladik, 2006).

Supra-threshold perceived intensities: Two series of four solutions of sodium chloride (32, 100, 320 and $1000 \mathrm{mM})$, two series of four sucrose solutions $(121,242,485$ and $970 \mathrm{mM})$, and two series of four PROP solutions $(0.1,0.32$, 
and $3.2 \mathrm{mM}$ ) were provided in a random order, with two water rinses between each trial (citric acid was not tested). The perceived intensity of each solution was marked by the subject on a 9-point scale labelled at the extremities with no taste [1] and extremely intense taste [9], and the intensity values obtained for the 4 concentrations of each taste were then added; thus, the possible range for these scores was 8-72. According to these scores, the study sample was divided into three groups of increasing taste perceived intensity, for each tested substance.

Global taste acuity score. We determined an individual Global Taste Acuity Score (GTAS) by grouping threshold data for each tested substance into terciles and attributing respectively score 3, 2, and 1, for the first, the second and the third tercile. The GTAS was then calculated as the sum of the score values. Thus in contrast to threshold concentrations, lower GTAS scores reflect poorer taste acuity. The study sample was also divided into three groups of increasing GTAS.

\section{Neophobia rating}

The French translation of the Food Neophobia Scale (FNS; Pliner \& Hobden, 1992), as described by Rigal et al. (2006), was used. Each subject at T1 and T2 completed the 13-item questionnaire with scaled responses from 1 to 4 (agree a lot, agree, disagree, disagree a lot). Individual FNS scores were calculated as a mean rating of the 13 questions, with reverse scoring for 7 items so that higher scores indicated greater neophobia.

\section{Food familiarity and food liking}

Each subject completed a 60-item Food Familiarity and Liking Questionnaire (FFLQ) at T1 and T2. The items were randomly presented. Food familiarity was first assessed by a binary response (Yes/No) to the question "Have you already tasted this food?" In case of a positive answer, the subject was asked to indicate his/her liking on a nine-point scale labelled from "I don't like at all" (rated 1) to "I like a lot" (rated 9).

The FFLQ included seven food categories (Rigal et al, 2006) which differ in the frequency of exposure: fruits and vegetables, calorie-reduced foods, breakfast foods, animal products, high energy foods, spices, and foods rarely or never served because of their very high caloric density, or because of their unusual occurrence in the French adolescent's diet.

Several scores were calculated for each subject from the FFLQ: (i) the number of unknown foods (sum of 'No' responses to the familiarity question); (ii) mean food liking (mean of all liking scores given for the foods that have been tasted); (iii) the number of foods that were preferred (rated $>6$ ) and the number of foods that were disliked (rated <4); (iv) food category likings (mean liking scores for each of the seven food categories, after discarding the "no" responses).

Cronbach's alphas were calculated at T1 for the FNS data and for the liking ratings in the various food 
categories. A satisfactory internal consistency was found for FNS (alpha=0.84), fruits and vegetables (alpha $=0.86$ ), and calorie-reduced foods (alpha $=0.65$ ). Lower Cronbach's alphas characterized the other food categories $(0.56 \leq$ alpha $\leq 0.59)$.

\section{Statistical analysis}

Changes in the BMI for age Z-scores and in the FNS and FFLQ scores were calculated as differences between measurements at T2 and T1 (T2 - T1). Statistica 6.0 software (Statsoft, Inc, Tulsa, OK, USA) was used to compute Cronbach's alphas and Pearson correlation coefficients between taste acuity variables and various parameters including gender, age, and T2 - T1 differences in FNS and FFLQ scores. However Spearman correlation coefficients have been used with PROP thresholds, considering the non-normality of the distribution of this variable (Shapiro-Wilk $W$ test for normality $=0.92, \mathrm{p}=0.01$ ). Differences between subjects grouped according to GTAS and supra-threshold rating scores were assessed using a Student's $t$ test.

\section{Results}

The mean taste recognition thresholds for sucrose $(29 \mathrm{mM})$, citric acid $(1.6 \mathrm{mM})$ and sodium chloride $(26.5 \mathrm{mM})$ of these obese adolescents were distributed within the usual range of adult population samples (Pasquet et al., 2002). We found in this sample a low proportion of PROP "non-tasters:" 6 adolescents (all girls) out of 39 with PROP threshold $>1 \times 10^{-1} \mathrm{mM}$ (see Anliker, Bartoshuk, Ferris, \& Hooks, 1991, for age-adjusted threshold criteria). There were significant correlations between taste thresholds for sucrose and sodium chloride and for sucrose and PROP ( $\mathrm{r}=0.49$ for both), and between thresholds for sodium chloride and citric acid and for sodium chloride and PROP ( $\mathrm{r}=0.40$ for both).

No significant relationships were observed, at T1, between any of the taste acuity variables and age, BMI for age, neophobia score, or the FFLQ variables, except a weak sex-effect for GTAS ( $\mathrm{p}=0.05$ ), with girls showing higher global acuity. However the results presented in Table 1 remained globally unchanged when controlling for sex. Partial correlation coefficients between GTAS and changes in neophobia or changes of the liking for fruit and vegetable are respectively $0.44(\mathrm{p}<0.01)$ and $-0.34(\mathrm{p}<0.05)$.

With regard to changes in food preferences from T1 to T2, liking for fruits and vegetables, breakfast foods and calorie-reduced foods increased significantly $(\mathrm{p}<0.05, \mathrm{p}=0.05$ and $\mathrm{p}<0.05$, respectively), whereas liking for animal products decreased $(\mathrm{p}<0.01)$. The number of unknown foods was also significantly reduced $(\mathrm{p}<0.001)$.

A tendency for food neophobia (FNS) to decrease between T1 and T2, as previously reported in the 72-subject 
sample (Rigal et al., 2006), was observed ( $<0.10$, unilateral $t$ - test). This decrease was correlated with an increase in mean food liking scores $(\mathrm{r}=-0.31, \mathrm{p}=0.05)$, a decrease in the number of food dislikes $(\mathrm{r}=0.49, \mathrm{p}<0.01)$ and an increase in liking for fruits and vegetables $(\mathrm{r}=-0.38, \mathrm{p}<0.05)$.

Interestingly, both the decrease in food dislikes and the increase in liking for fruits and vegetables were correlated with a decrease in the BMI for age (respectively $\mathrm{r}=0.32, \mathrm{p}<0.05$ and $\mathrm{r}=-0.39, \mathrm{p}=0.01$ ). However, no relationship was observed with duration of stay.

Table 1

\begin{tabular}{|c|c|c|c|c|c|c|}
\hline & Citric acid a & $\mathrm{NaCl}_{\text {a }}$ & Sucrose $_{a}$ & PROP $_{b}$ & GTAS c & $\begin{array}{c}\text { PROP } \\
\text { perceived intensity c }\end{array}$ \\
\hline Changes during WRS (T2-T1) & -0.32 * & -0.24 & $-0.47^{* \star}$ & $-0,34^{*}$ & $0.46 * *$ & $0.33^{*}$ \\
\hline
\end{tabular}

Food neophobia score (FNS)

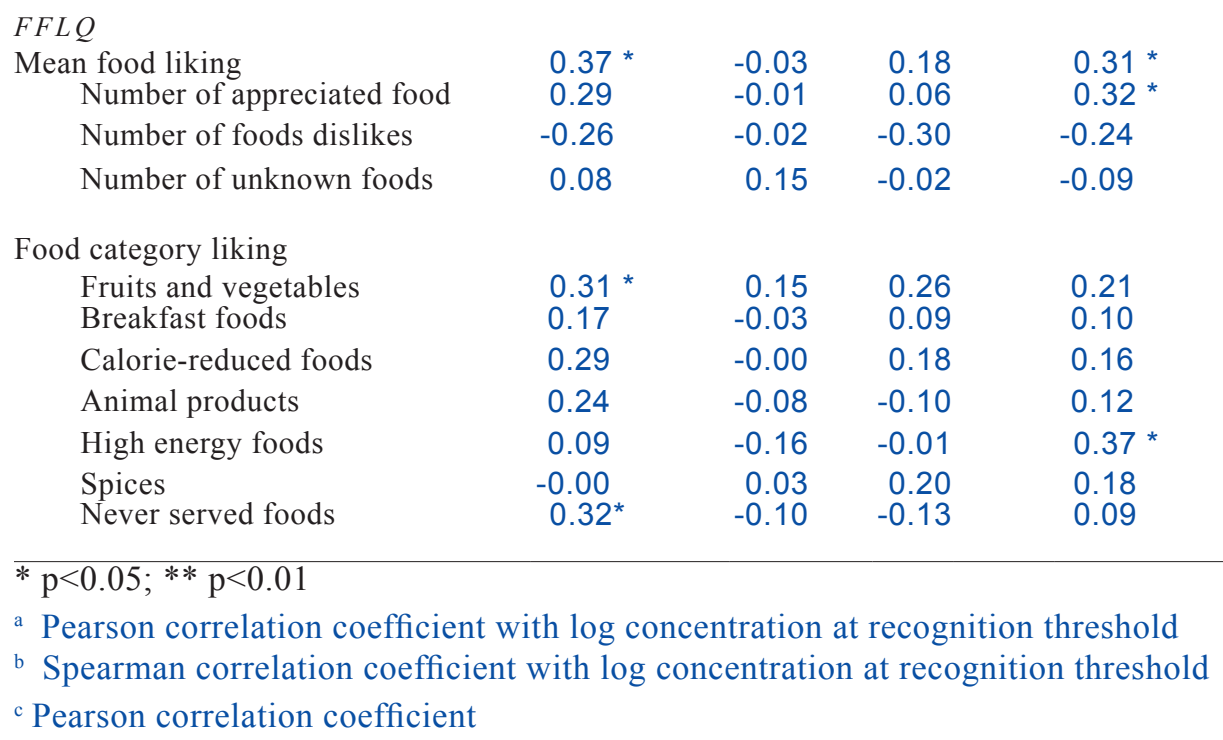

Table I. Relationships between recognition thresholds, Global Taste Acuity Score (GTAS) and PROP perceived intensity, and changes in Food Neophobia Score (FNS) and in the Food Frequency Liking Questionnaire (FFLQ) variables during the weight reduction session (WRS).

Table I shows the relationships between taste acuity data and food related behavioural changes during the WRS. Recall that lower taste thresholds reflect greater taste acuity. The entire PROP threshold distribution was used instead of the classical dichotomy between tasters and non-tasters, due to the small number of non-tasters in our sample. 
Significant negative correlations were observed between citric acid, sucrose and PROP thresholds and changes in food neophobia scores. Significant positive correlations were observed between citric acid and PROP thresholds and changes in food liking, between PROP thresholds and changes in the number of appreciated foods, between citric acid thresholds and changes in liking for fruits and vegetables, and between PROP thresholds and changes in liking for high energy foods. GTAS was correlated positively with the changes in food neophobia scores, and negatively with the changes in liking for fruits and vegetables. Thus, individuals who evidenced poorer taste acuity on these various measures of threshold sensitivity tended to show greater declines in food neophobia and greater increases in liking for some categories of food during WRS than did those with better taste acuity.

Significant negative correlations were observed between citric acid, sucrose and PROP thresholds and changes in food neophobia scores. Significant positive correlations were observed between citric acid and PROP thresholds and changes in food liking, between PROP thresholds and changes in the number of appreciated foods, between citric acid thresholds and changes in liking for fruits and vegetables, and between PROP thresholds and changes in liking for high energy foods. GTAS was correlated positively with the changes in food neophobia scores, and negatively with the changes in liking for fruits and vegetables. Thus, individuals who evidenced poorer taste acuity on these various measures of threshold sensitivity tended to show greater declines in food neophobia and greater increases in liking for some categories of food during WRS than did those with better taste acuity.

With regard to supra-threshold perceived intensities, only PROP data are reported in Table I since weak correlations were observed for sucrose and $\mathrm{NaCl}$. However, PROP perceived intensity was positively correlated with changes in neophobia (lower ratings, greater declines), and negatively with changes in liking for fruits and vegetables and for spices, consistent with the general direction of associations observed with the threshold measures.

Comparisons among subjects grouped according to either GTAS or PROP supra-threshold perception scores are depicted in Figures 1 and 2. These illustrate two major relationships observed in this study: between GTAS and changes in food neophobia and between perceived intensity of PROP bitterness and changes in liking for fruits and vegetables during WRS.

Figure 1

Changes in Food Neophobia Score (FNS) during the Weight Reduction Session (WRS) according to Global Taste Acuity Score (GTAS). The study sample is divided into three groups of subjects ( $n=11,14$, and 14, respectively) of increasing taste acuity including respectively 5,11 , and 12 girls. 

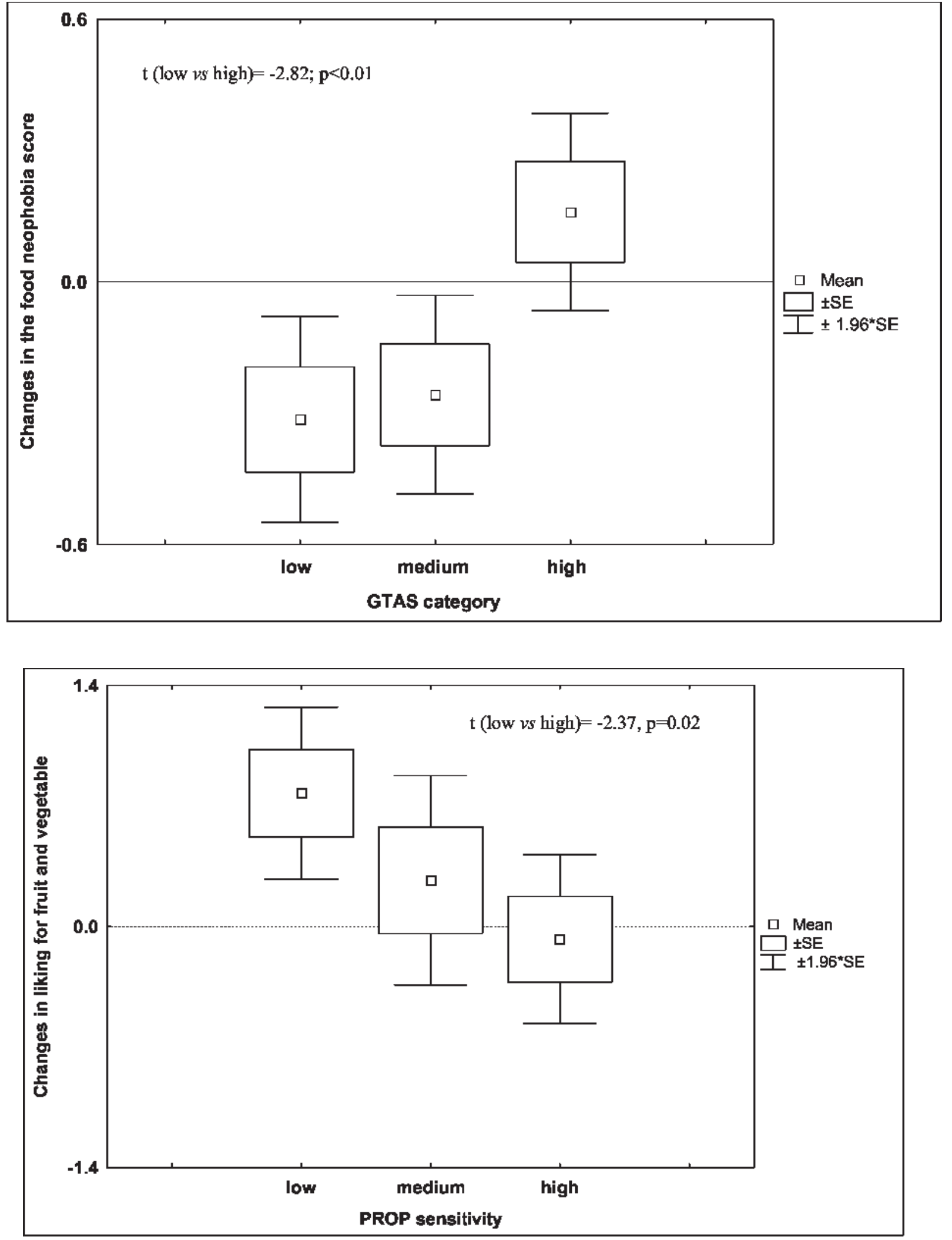

Figure 2

Changes in the liking for fruit and vegetable during the Weight Reduction Session (WRS) according to perceived intensity of supra-threshold PROP. The study sample is divided into three groups of 13 subjects of increasing PROP perceived intensity including respectively 7,10 , and 11 girls. 


\section{Discussion}

Taste responsiveness, whether determined on the basis of taste recognition thresholds or supra-threshold intensity ratings, appears to mediate food-related attitudinal changes during WRS for obese adolescents. However the relationship with supra-threshold intensity ratings was observed only for PROP, not for sucrose or sodium chloride. Methodological reasons, such as the range of concentrations tested together with the use of a nine-point scale that may be subject to ceiling effects (Bartoshuk, Duffy, Hayes, Moskowitz \& Snider, 2006) could contribute to the poor correlations observed with ratings of the other tastes.

Nevertheless, our study is, to our knowledge, unique in showing a relationship between taste acuity and changes in food attitudinal traits following a change in available foods, meal structure and educational context. Greater taste acuity seems to make it more difficult to overcome food neophobia, and to accept healthy foods, notably fruits and vegetables.

If one considers food neophobia to be a temperamental trait (at least when measured by FNS; Rigal et al., 2006), the relationship that we found between gustatory perception and changes in food neophobia highlights the relationship between psychological traits and sensory factors. Such a relationship was reported by Mascie-Taylor, McManus, MacLarnon, \& Lanigan (1983), who showed that PTC non-tasters are significantly more placid and relaxed than their more apprehensive and tense taster counterparts. The psychological traits linked to taste sensitivity can even be observed during early infancy, according to Chiva (1985), who measured the intensity of reactions to taste stimuli (sucrose, sodium chloride, quinine sulfate and citric acid) in 34 babies tested during the first week after birth. The infants were individually followed for global food preferences and reactivity until two years of age, and the greater their taste reactivity in infancy, the greater their pickiness and unpredictable behaviour towards foods at the age of two. In this context, food neophobia can be seen as an adaptive temperamental trait reducing the risk of ingesting toxic foods, and the most sensitive individuals tend to develop the greatest neophobia.

Another relationship may be suggested by the results of psychophysical studies of young and middle-aged adults (Goldstein, Daun, \& Tepper, 2005; Simchen, Koebnick, Hoyer, Issanchou, \& Zunft, 2006) showing that PROP non-tasters and those less sensitive to citric acid and quinine have higher BMIs than more sensitive individuals. Thus, lower taste acuity, together with temperamental traits such as neophilia and placidity, could favour weight gain through a higher adaptability to an eating environment promoting excessive calorie consumption, as in western affluent societies. In the context of our study focusing on massively obese adolescents, the same plasticity of the less sensitive subjects may explain the greater increase in preferences for fruits and vegetables that we observed in the environmental context of a weight reduction session, as well as the decrease in neophobia, although this temperamental trait — which varies little over the life span — can be only slightly changed from its original trajectory (Rigal et al., 2006). Among these obese adolescents, those who have high taste sensitivity may be less likely to benefit from the WRS, and probably need an adapted weight reduction program. 
In conclusion, the results of this study suggest that taste sensitivity, perhaps especially PROP sensitivity, may reduce the likelihood and/or magnitude of food-related attitudinal changes, particularly vis-à-vis neophobia and liking for fruits and vegetables. This should be taken into account in attempts to optimize the outcomes of weight reduction programs in obese adolescents.

\section{Acknowledgements}

This work was supported by a grant from the Centre d'Information des Viandes. We are indebted to our colleague André Marez and to Valérie Coppet, dietetician and Evelyne Mateusiak, nurse at the Margency Centre, for helping us in this study, and to all adolescents who kindly participated to the tests. Special thanks are due to anonymous reviewers and to Beverly Cowart for many constructive remarks and editorial suggestions leading us to clarify the presentation of our results. 


\section{References}

Anliker, J. A., Bartoshuk, L., Ferris, A. M., \& Hooks, L. D. (1991). Children's food preferences and genetic sensitivity to the bitter taste of 6-n-propylthiouracil (PROP). Americal Journal of Clinical Nutrition, 54, 316-320.

Bartoshuk L. M., Duffy V. B., Hayes J. E., Moskowitz H. R. \& Snider D. J. (2006) Psychophysics of sweet and fat perception in obesity: problems, solutions and new perspectives. Philosophical Transactions of the Royal Society, B, 361, 1137-1148.

Carter, E., Donley, V., Sonson, C., Santaniello, N., Staley, M., \& Raudenbush, B. (2000). PTC sensitivity differentiates food neophobics and food neophilics. Conference of the Society for the Study of Ingestive Behavior (August, 2000), Dublin, Ireland.

Centre for Disease Control and Prevention/National Centre for Health Statistics. CDC Growth Charts: United States. Department of Health and Human Services, Hyattsville, 2000.

Chiva, M., (1985). Le doux et l'amer : sensation gustative, émotion et communication chez le jeune enfant. Presses Universitaires de France, Paris.

Cornsweet, T. N. (1962). The staircase-method in psychophysics. American Journal of Psychology, 75, 485-491.

Goldstein, G. L., Daun H., \& Tepper, B. J. (2005). Adiposity in middle-aged women associates with genetic taste blindness to 6-n-Propylthiouracil. Obesity Research, 13, 1017-1023.

Mascie-Taylor, C. G. N., McManus, I. C., MacLarnon, A. M., \& Lanigan, P. M. (1983). The association between phenylthiocarbamide (PTC) tasting ability and psychometric variables. Behaviour Genetics, 13/2, 191-196.

Pasquet, P., Oberti, B., El Ati, J., \& Hladik, C. M. (2002). Relationships between threshold-based PROP sensitivity and food preferences of Tunisians. Appetite, 39, 167-173.

Pasquet, P., Monneuse, M. O., Simmen, B., Marez, A., \& Hladik, C. M. (2006). Relationship between taste thresholds and hunger under debate. Appetite, 46, 63-66.

Pliner, P., \& Hobden, K. (1992). Development of a scale to measure the trait of food neophobia in humans. Appetite 19, 105-120.

Raudenbush, B., Corley, N., Flower, N. R., Kozlowski, A., \& Meyer, B. (2003). Cephalic phase salivary response differences characterize level of food neophobia. Appetite, 41, 21 1-212.

Rigal. N., Frelut, M. L., Monneuse, M. O., Simmen, B., Hladik, C. M., \& Pasquet, P. (2006). Food neophobia in the context of a varied diet induced by a weight reduction program in massively obese adolescents. Appetite, 46, 207-214

Simchen, U., Koebnick, C., Hoyer, S., Issanchou, S., \& Zunft, H.-JF. (2006). Odour and taste sensitivity is associated with body weight and extent of misreporting of body weight. European Journal of Clinical Nutrition, 60, 698705.

Tanner, J .M. (1962) Growth at adolescence. 2nd Ed. Oxford, England: Blackwell Scientific Publication, 326 p. 